\title{
Early-onset central diabetes insipidus is associated with de novo arginine vasopressin-neurophysin II or Wolfram syndrome 1 gene mutations
}

\author{
Silverio Perrotta, Natascia Di lorgi ${ }^{1}$, Fulvio Della Ragione ${ }^{2}$, Saverio Scianguetta, \\ Adriana Borriello², Anna Elsa Maria Allegri' , Marcella Ferraro, Claudia Santoro, \\ Flavia Napoli ${ }^{3}$, Annalisa Calcagno', Marta Giaccardi ${ }^{1}$, Marco Cappa4, \\ Maria Carolina Salerno5 ${ }^{5}$ Domenico Cozzolino ${ }^{6}$ and Mohamad Maghnie ${ }^{1}$ \\ Dipartimento della Donna, del Bambino e di Chirurgia Generale e Specialistica, Second University of Naples, via De \\ Crecchio 4, Naples, Italy, 'Istituto Giannina Gaslini, University of Genova, 16147 Genova, Italy, ${ }^{2}$ Department of \\ Biochemistry, Biophysics, and General Pathology, Second University of Naples, via De Crecchio 7, Naples, Italy, \\ ${ }^{3}$ Istituto Giannina Gaslini, Largo Gerolamo Gaslini 5, 16147 Genova, Italy, ${ }^{4}$ Unit of Endocrinology and Diabetology, \\ Bambino Gesù Children's Hospital, IRCCS, Rome, Italy, ${ }^{5}$ Pediatric Endocrinology Unit, Department of Translational \\ Medical Sciences, University 'Federico II' of Naples, Naples, Italy and 'Division of Internal Medicine, \\ Second University of Naples, 80100 Naples, Italy
}

Correspondence should be addressed to M Maghnie

Email

mohamadmaghnie@ ospedale-gaslini.ge.it or Mohamad.Maghnie@unige.it

\begin{abstract}
Objective: Idiopathic early-onset central diabetes insipidus (CDI) might be due to mutations of arginine vasopressinneurophysin II (AVP-NPII (AVP)) or wolframin (WFS1) genes.

Design and methods: Sequencing of AVP and WFS1 genes was performed in nine children with CDI, aged between 9 and 68 months, and negative family history for polyuria and polydipsia.

Results: Two patients carried a mutation in the AVP gene: a heterozygous G-to-T transition at nucleotide position 322 of exon 2 (c.322G > T) resulting in a stop codon at position 108 (p.Glu108X), and a novel deletion from nucleotide 52 to 54 (c.52_54delTCC) producing a deletion of a serine at position 18 (p.Ser18del) of the AVP pre-prohormone signal peptide. A third patient carried two heterozygous mutations in the WFS1 gene localized on different alleles. The first change was A-to-G transition at nucleotide 997 in exon 8 (c.997A > G), resulting in a valine residue at position 333 in place of isoleucine (p.lle333Val). The second novel mutation was a 3 bp insertion in exon 8, c.2392_2393insACG causing the addition of an aspartate residue at position 797 and the maintenance of the correct open reading frame (p. Asp797_Val798insAsp). While similar WFS1 protein levels were detected in fibroblasts from healthy subjects and from the patient and his parents, a major sensitivity to staurosporine-induced apoptosis was observed in the patient fibroblasts as well as in patients with Wolfram syndrome.

Conclusions: Early-onset CDI is associated with de novo mutations of the AVP gene and with hereditary WFS1 gene changes. These findings have valuable implications for management and genetic counseling.

\section{Introduction}

Central diabetes insipidus (CDI) is a condition characterized by polyuria and polydipsia due to arginine vasopressin (AVP) deficiency. The disease is mainly due to the selective destruction of the neurons deriving from supraoptic and paraventricular hypothalamic nuclei $(1,2)$ and in few instances to rare inherited diseases (OMIM: *192340, \#125700) $(3,4)$.

While the prevalence of idiopathic CDI is reported to be in the range of $4-55 \%$ of affected subjects $(1,5)$, the identification of anti-vasopressin-cell antibodies in some
(C) 2015 European Society of Endocrinology Printed in Great Britain
Published by Bioscientifica Ltd. 
patients (6) and of vascular injury at the inferior hypophyseal arteries in others (7) have shed additional light on the pathogenesis of CDI. Indeed, the etiological diagnosis remains a challenge in several cases.

In a large cohort of patients with CDI of different etiologies, we recognized that children with autosomal dominant CDI are diagnosed within the age of 7 years (1). This observation led us to propose the hypothesis that children with idiopathic CDI presenting early in life might have de novo gene mutations affecting the AVP-neurophysin II $(A V P-N P I I(A V P))$ gene. On the other hand, as Wolfram syndrome is considered as a progressive neurodegenerative disorder with severe neurological abnormalities and often resulting in death between the third or fourth decade of life (4), we wondered whether WFS1 mutations might cause selective hypothalamic nuclei neurodegeneration leading to early-onset isolated CDI, even though WFS1 gene mutations have never been reported in association with isolated CDI till date.

Herein, we report the results of AVP and WFS1 genetargeted sequencing performed in nine children diagnosed with non-hereditary CDI presented within the first 7 years of life in order to identify potential mutations underlying their condition.

\section{Subjects and methods}

\section{Patients}

Our study included nine children with early-onset polyuria and polydipsia from families with no history of CDI. Patients were referred to the Pediatric Endocrine Unit, Gaslini Institute, University of Genoa, between January 2003 and April 2008. Genetic analysis was performed at a median age of 7 years (range $4-26$ years).

The diagnosis of isolated CDI was based on a standard protocol as reported previously (5), namely the criteria for the enrolment of patients, which included: i) age at onset of polyuria and polydipsia between 1 month and 7 years; ii) no family history for CDI; iii) isolated AVP deficiency; and iv) normal magnetic resonance imaging (MRI) of the brain including the brainstem, the cerebellum, and optic nerves as well as the hypothalamic-pituitary region; the presence or absence of posterior pituitary hyperintensity (PPI) was not an exclusion criterion. MRI was performed at the time of diagnosis and during follow-up (last in July 2014) as reported previously (5). The pituitary-thyroid-adrenal axis was assessed by measuring serum free thyroxine, thyrotropin, and serum cortisol once every 12 months; growth hormone deficiency was ruled out based on the presence of normal growth.

This study was approved by the institutional review board, and written informed consent was obtained from the parents for study enrolment and genetic analysis.

\section{Reagents}

Staurosporine was obtained from BIOMOL International, LP (Plymouth Meeting, PA, USA). Lipofectamine 2000 was obtained from Invitrogen Corporation. The pcDNA3-FlagHA-WFS1 (encoding Wolframin) and rabbit polyclonal antibodies against human Wolframin were kindly given by Prof. Fumihiko Urano, University of Massachusetts Medical School (UMMS, Worcester, MA, USA). Rabbit polyclonal antibodies against total and cleaved poly(ADPribose polymerase) (PARP) were generously provided by Prof. Piera Quesada, University of Naples 'Federico II' (Naples, Italy). Polyclonal antibodies against $\beta$-actin were obtained from Santa Cruz Biotechnology.

\section{Mutation analysis}

Genomic DNA was extracted from peripheral blood leukocytes following standard procedures. All exons and the intron-exon boundaries of the AVP (OMIM ID: 192340; ENSEMBL ID: ENSG00000101200) and Wolfram syndrome 1 (WFS1) (OMIM ID: 606201; ENSEMBL ID: ENSG00000109501) genes were PCR amplified using specific primers (Primer3 v. 0.4.0, freeware online). Detailed protocols and primer sequences are available on request. The products were sequenced using the ABI 310 DNA Sequencer and the ABI PRISM Dye Terminator Cycle Sequencing Reaction kit (Applied Biosystems), according to the manufacturer's instructions.

\section{Primary fibroblast isolation and cell cultures}

Primary cultures of fibroblasts were established as reported previously (8). Particularly, fibroblasts were obtained from: i) healthy subjects; ii) the patient identified in this study and his parents; and iii) two additional patients with Wolfram syndrome previously characterized in our departments. These two patients showed the following WFS1 mutations: patient WF1 (c.1514G>A; c.1620delGTG corresponding to C505Y; V540del) and patient WF2 (c.1514G $>$ A; c. $1628 \mathrm{~T}>\mathrm{G}$ corresponding to C505Y; L543R). Primary fibroblasts were cultured at $37^{\circ} \mathrm{C}$ in DMEM (Life Technologies) supplemented with $10 \%$ FCS and $2 \mathrm{mM}$ glutamine. 
Non-transformed human prostate epithelial (EPN) cells were cultured as reported previously (9). This cell line was employed as it is transfectable with high efficiency and could provide a reliable experimental control for wolframin protein expression.

\section{Quantitative real-time RT-PCR}

Total RNA was extracted from cultured fibroblasts of patients 6 and 3 healthy subjects using TRIZOL (Invitrogen), and treated with DNAse (Promega) according to the manufacturer's recommendations. High-quality total RNA was then transcribed to first-strand cDNA using random hexamers and Superscript III (Invitrogen).

To quantify WFS1 gene expression, $1.5 \mu \mathrm{g}$ of total RNA were retrotranscribed to cDNA templates and amplified in triplicates using SYBR Green PCR Master Mix (Bio-Rad) and specific primers, i.e., a total volume of $25 \mu \mathrm{l}$ reaction contained $2 \mu \mathrm{l}$ of cDNA, $12.5 \mu \mathrm{l}$ of SYBR Green Master Mix, and $10 \mu \mathrm{l}$ primer $\operatorname{mix}(10 \mathrm{mM})$. Primers were designed using the Primer Express 2.0 program (Applied Biosystems). Detailed conditions (methods and primer sequences) may be available on request. The thermal cycling program was performed as follows: a first step at $95^{\circ} \mathrm{C}$ for $10 \mathrm{~min}$, followed by 40 cycles of amplification at $95^{\circ} \mathrm{C}$ for $15 \mathrm{~s}$ and $60^{\circ} \mathrm{C}$ for $60 \mathrm{~s}$.

Gene expression profiling was achieved using the comparative cycle threshold $(\mathrm{Ct})$ method of relative quantization (RQ) to the housekeeping gene. To normalize data, $\Delta \Delta C \mathrm{t}$ was calculated for each sample using the mean of its $\Delta C \mathrm{t}$ values subtracted from the mean $\Delta C \mathrm{t}$ value measured in the entire population of healthy subjects, considered as a calibration. The RQ value was expressed as $2^{-\Delta \Delta C t}$. Real-time PCR products were analyzed using the Icycler Software (Bio-Rad Laboratories).

\section{Staurosporine-induced apoptosis and protein extraction}

To test the sensitivity of cells to staurosporine-induced apoptosis, primary fibroblasts were cultured until they reached $70 \%$ confluence and then treated for $4 \mathrm{~h}$ with $1 \mu \mathrm{M}$ staurosporine. Cells were collected and resuspended in lysis buffer containing $1 \%$ deoxycolate, $1 \%$ Triton $\mathrm{X}-100,0.1 \%$ SDS, $150 \mathrm{mM} \mathrm{NaCl}$, and protease inhibitors $(8,9)$, and incubated for $1 \mathrm{~h}$ at $4{ }^{\circ} \mathrm{C}$. Samples were, then, centrifuged and the supernatants processed by immunoblotting in order to evaluate PARP cleavage.

For the detection of wolframin, a different lysis buffer was employed, i.e., the buffer contained $6.7 \mathrm{M}$ urea,
$10 \mathrm{mM}$ Tris-Cl pH 6.8, 1 mM dithiothreitol, 10\% glycerol, $1 \%$ SDS, and phosphatase and protease inhibitors. After incubation for $1 \mathrm{~h}$ at $4{ }^{\circ} \mathrm{C}$, the supernatant was recovered and employed for the detection of wolframin by immunoblotting. A detailed description of the immunoblotting method is reported in references $(8,9)$.

\section{Immunofluorescence}

Human fibroblast cells were fixed with $4 \%$ paraformaldehyde in PBS for $30 \mathrm{~min}$, followed by incubation in ice-cold methanol for additional $30 \mathrm{~min}$. Antigen retrieval was then performed with $1 \%$ SDS for $3 \mathrm{~min}$, followed by three steps of washing with PBS for 5 min each. Unspecific sites were, then, blocked by incubating slides with PBS containing $6 \% \mathrm{BSA}$ for $1 \mathrm{~h}$ before application of a primary antibody diluted in PBS containing 1\% BSA. Incubation with anti-wolframin (1:25 dilution) was performed for $75 \mathrm{~min}$ at room temperature (RT), and a biotinylated antirabbit IgG secondary antibody (Vector BA-1000, 1:200 dilution in PBS containing 1\% BSA) was then added for $1 \mathrm{~h}$ at RT. Slides were washed three times with PBS (5 min each) and incubated for $1 \mathrm{~h}$ with Qdot streptavidin conjugate (Invitrogen Q10121MP), diluted to an optimal concentration (titrate between 10 and $40 \mathrm{nM}$ for optimal results) with PBS containing 1\% BSA. At the end of incubation, cells were washed three times with PBS (5 min each). Finally, slides were mounted using one drop of Cytoseal 60 (The Science Company, Denver, CO, USA) and specimens allowed to cure for at least $4 \mathrm{~h}$ before imaging. Images were captured using a Leica Laser Scanning Confocal Microscope TCS SP2 (Leica Microsystems, Heidelberg, Germany).

\section{EPN cell transfection}

In order to confirm the specificity of the antibodies employed to assess wolframin protein expression, EPN cells were used to generate a reliable positive experimental control, i.e., EPN cells were transiently transfected with pcDNA3-Flag-HA-WFS1 plasmid encoding human wolframin using Lipofectamine 2000 (8). EPN cells were grown until they reached $\sim 60 \%$ confluence in culture medium without antibiotics and collected after $48 \mathrm{~h}$ of transfection. Cell pellets were then centrifuged and cellular extracts processed as aforementioned.

\section{Multiplex ligation-dependent probe amplification}

Multiplex ligation-dependent probe amplification (MLPA) was performed in order to rule out the potential presence 
of deletions or duplications in patients for whom mutations in WFS1 were not found. MLPA was performed with SALSA MLPA probemix P163-D1 GJB-WFS1 (MRCHolland, Amsterdam, The Netherlands) and included probes for each of the eight WFS1 exons.

The reactions were carried out according to the manufacturer's instructions using the EK1 reagent kit (MRC-Holland). MLPA products were separated by ABI3130XL Genetic Analyzer (Applied Biosystems), quantified using the 'Coffalyser' Software (MRC-Holland) and compared with a DNA pool from normal subjects.

\section{Results}

\section{Clinical description of study cohort}

The nine subjects fulfilled the criteria of idiopathic CDI and were, thus, enrolled in the study for genetic analysis. Clinical and neuroimaging characteristics of the cohort are given in Table 1.

The median age at the time of diagnosis was 21 months with a similar number of males (four cases) and females (five cases). None of the patients had a family history of polyuria and polydipsia. PPI was absent on the first MRI in four patients and present in its normal location in five subjects (Fig. 1). The anterior pituitary gland and the pituitary stalk size and shape were normal in all patients, and none displayed CNS malformations. PPI was no longer present at the last MRI imaging evaluation in all but one patient (Table 2). Anterior pituitary function was normal at the time of first evaluation and during the follow-up (data not shown).

\section{Genetic profiling of idiopathic CDI patients}

All exons of the AVP and WFS1 genes were amplified and sequenced in the whole cohort. Two patients carried

Table 1 Characteristics of the nine patients with central diabetes insipidus.

\begin{tabular}{|c|c|c|c|c|c|}
\hline $\begin{array}{l}\text { Patient } \\
\text { no. }\end{array}$ & Sex & $\begin{array}{c}\text { Age at } \\
\text { onset } \\
\text { (months) }\end{array}$ & $\begin{array}{c}\text { Age at } \\
\text { diagnosis } \\
\text { (months) }\end{array}$ & $\begin{array}{c}\text { Age at } \\
\text { first MRI } \\
\text { (months) }\end{array}$ & $\begin{array}{l}\text { Posterior } \\
\text { pituitary } \\
\text { hyperintensity }\end{array}$ \\
\hline 1 & Female & 43 & 57 & 64 & Present \\
\hline 2 & Female & 12 & 18 & 22 & Present \\
\hline 3 & Female & 18 & 20 & 21 & Present \\
\hline 4 & Female & 48 & 48 & 50 & Present \\
\hline 5 & Male & 16 & 21 & 42 & Absent \\
\hline 6 & Male & 30 & 34 & 38 & Absent \\
\hline 7 & Male & 68 & 75 & 77 & Absent \\
\hline 8 & Female & 9 & 9 & 14 & Present \\
\hline 9 & Male & 15 & 18 & 21 & Absent \\
\hline
\end{tabular}

a mutation in the AVP gene (Fig. 2) and one in the WFS1 gene. In patient 2 , the direct sequencing of the $A V P$ gene revealed the presence of a heterozygous G-to-T transition at nucleotide position 322 of exon 2 (c.322G $>$ T). This previously described mutation (10) produced a stop codon at position 108 (p.Glu108X) (Fig. 2A). Patient 4 showed an unreported deletion from nucleotide position 52 to 54 (c.52_54delTCC) that produced the deletion of a serine residue at position 18 (p.Ser18del) of the AVP preprohormone signal peptide (Fig. 2B). In both patients, no other alterations were observed in the remaining coding region and the mutant alleles were not found in the parents and in the unaffected family members. Paternity testing was performed according to ISO 17025 standard (11). Based on this test, we calculated a probability of paternity of $99.99 \%$. Figure $1 \mathrm{C}$ summarizes the identified mutations that were not found in 200 healthy subjects. The WFS1 gene molecular screening of patient 6 revealed the presence of two heterozygous mutations, each localized on a different allele. The first change was A-to-G transition at nucleotide position 997 in exon 8 (c.997A $>\mathrm{G})$ resulting in a valine residue at position 333 in place of an isoleucine residue (p.Ile333Val) (Fig. 3A). The second and novel mutation was a $3 \mathrm{bp}$ insertion in exon 8, c.2392_2393insACG, which led to the addition of a third consecutive aspartic acid residue at position 797 and the maintenance of the correct open reading frame (p. Asp797_Val798insAsp) (Fig. 3B). The patient inherited c.997A $>\mathrm{G}$ and the insertion from the mother and the father respectively (both not affected by CDI). The genetic change of $3 \mathrm{bp}$ insertion in exon 8 , c.2392_2393insACG, was also evidenced in the unaffected patient's brother. This change was not found in 200 healthy subjects. This $3 \mathrm{bp}$ insertion was located in a region evolutionarily conserved among distant species such as human, mouse, rat, chicken, frog, and zebrafish, strongly suggesting that the domain may be relevant to the protein function (Fig. 3C).

\section{The identified WFS1 mutations did not affect wolframin expression}

To verify the effect of c.2392_2393insACG and c.997A > G (mutations on the WFS1 transcript in the proband, his father, and mother), an appropriate amount of the transcript was investigated by quantitative PCR using RNA prepared from fibroblasts. Interestingly, no difference in WFS1 transcript levels was found compared with control (data not shown). 

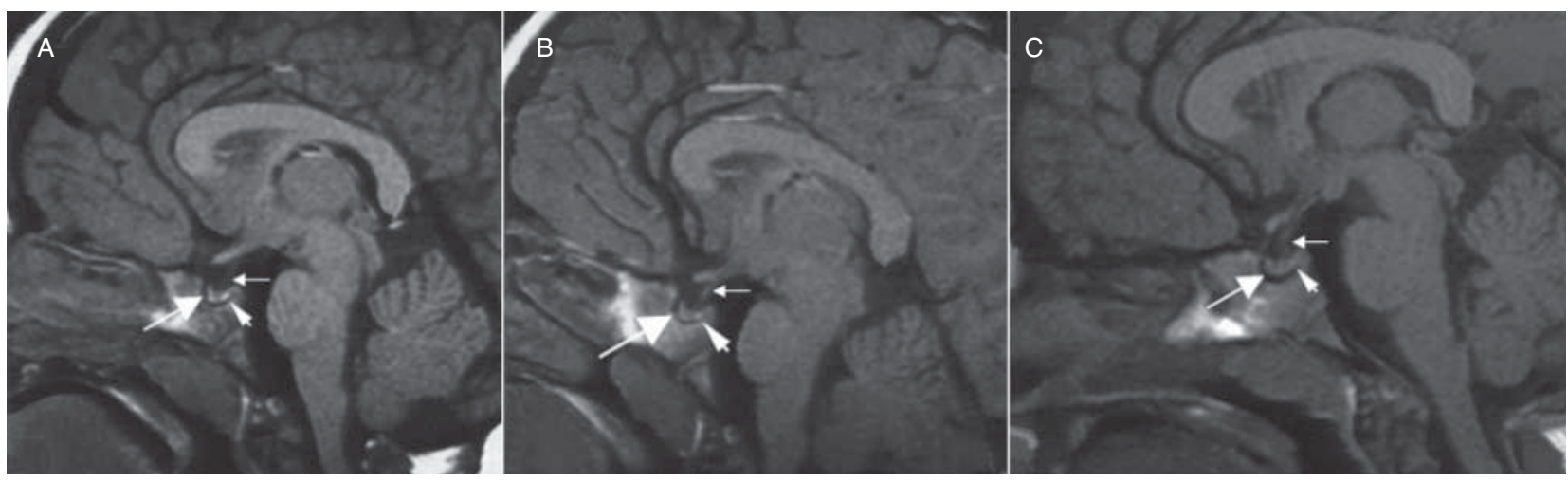

\section{Figure 1}

Sagittal (A, B and C) T1-weighted magnetic resonance imaging (MRI) in patient 2 carrying a mutation in the AVP gene.

(A) Normal anterior pituitary (white arrow) and pituitary stalk (small white arrow) size, and normal posterior pituitary hyperintensity (PPI) (white arrowhead) at the time of first MRI.
To evaluate whether or not the identified mutations affected wolframin protein content, primary fibroblast cultures were established from the WFS1-mutated patient, his relatives, and normal controls $(n=4)$. The level of protein expression was then assessed by immunoblotting. No significant changes in protein levels were observed in primary fibroblasts of patients compared with his parents or a healthy subject (Fig. 4).

EPN cells transfected with a plasmid encoding wolframin were also analyzed and used as positive control, in order to confirm the specificity of the antibodies employed (Fig. 4).

As the identified mutations did not result in alterations of wolframin protein expression, we investigated whether the genetic changes affected protein cellular distribution. Thus, wolframin cellular localization was assessed by immunofluorescence in fibroblasts purified from the patient, his relatives, and healthy controls. (small white arrow) size, and decrease in the signal intensity of the PPI (arrowhead) at the time of second MRI. (C) Normal anterior pituitary (white arrow) and pituitary stalk (small white arrow) size, and disapperance of posterior pituitary signal intensity (arrowhead) at the time of the last and first MRI.

As shown in Fig. 5, the presence of WFS1 mutations did not affect the cellular compartmentalization of wolframin protein. Taken together, these findings implied that the WFS1 mutations identified in our patient did not modify wolframin expression or its cellular compartmentalization.

\section{The identified WFS1 mutations induce functional changes in mechanisms of action of wolframin}

In agreement with our findings, a recent study has demonstrated that missense WFS1 mutations might leave wolframin protein level and its cellular localization unmodified (12). Conversely, the authors demonstrated that WFS1 mutations may functionally affect the protein causing a major sensitivity of fibroblasts from patients with Wolfram syndrome to the staurosporine-dependent apoptosis (12). To verify whether functional changes in

Table 2 Follow-up of brain magnetic resonance imaging (MRI) of the three patients with gene mutations. In patient 1, posterior pituitary hyperintensity (PPI) was absent at the age of 78 months. In patient 3, PPI was absent at the age of 64 months. In patient 8 , PPI was absent at the age of 59 months.

\begin{tabular}{|c|c|c|c|c|c|}
\hline \multirow[b]{2}{*}{ Patient no. } & \multicolumn{2}{|c|}{ Second MRI } & \multicolumn{2}{|c|}{ Third MRI } & \multirow[b]{2}{*}{ Mutation } \\
\hline & Age (months) & $\begin{array}{l}\text { Posterior pituitary } \\
\text { hyperintensity }\end{array}$ & Age (months) & $\begin{array}{l}\text { Posterior pituitary } \\
\text { hyperintensity }\end{array}$ & \\
\hline 2 & 130 & Present & Not available & Absent & AVP gene: c322G > T (p.Glu108X) \\
\hline 4 & 97 & Reduced & 105 & Absent & AVP gene: c.52 54delTCC (p.Ser18del) \\
\hline 6 & 57 & Absent & 72 & Absent & $\begin{array}{l}\text { WFS1 gene: c.997A> G (p.Ile333Val); c.2392_ } \\
\text { 2393insACG (p.Asp797_Val798insAsp) }\end{array}$ \\
\hline
\end{tabular}


A

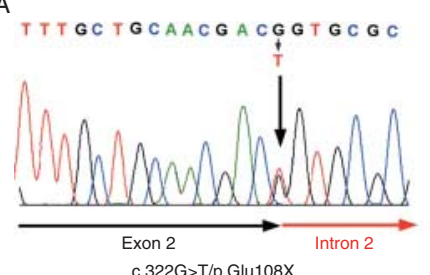

.322G>T/p.Glu108X

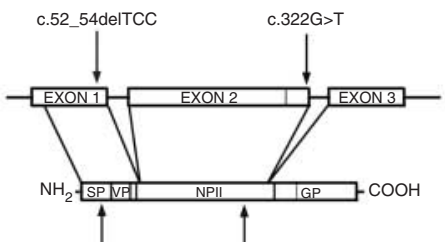

Figure 2

Alterations of the vasopressin-neurophysin II (AVP) gene in patients with central diabetes insipidus. (A) AVP sequence revealed the presence of a heterozygous G-to-T transition at nucleotide position 322 of exon 2 (322G $>$ T). The mutation produced a stop codon (TAG) at position 108 in place of the expected glutamic acid (GAG). (B) The sequence showed a deletion from nucleotide position 52 to 54 (delTCC52-54), that produced the absence of a serine residue at position 18 (S18del) of the AVP pre-prohormone signal peptide. (C) The scheme summarizes the genetic changes reported in (A) and (B).

wolframin function occurred in the presence of the WFS1 mutations identified in our patient, assessment of staurosporine-induced apoptosis was performed in cultures of primary fibroblasts (12). In particular, cells were exposed to staurosporine, and a key marker of apoptosis, i.e., PARP cleavage, was evaluated. Intriguingly, treatment with staurosporine caused an increased PARP cleavage only in fibroblasts prepared from the patient and not in those derived from his relatives or healthy donors (Fig. 6). This finding implies that the identified mutations resulted in a major sensitivity to staurosporine-induced apoptosis and demonstrates that these mutations were associated with functional changes in the mechanism of action of wolframin. The staurosporine test was also performed on fibroblasts from two additional patients affected by typical Wolfram syndrome. The results obtained indicated that the occurrence of mutated WFS1 gene might cause, at least in some cases, an increased apoptotic response (Fig. 6).

\section{MLPA analysis}

MLPA was performed to investigate the presence of copy number changes in patients in whom WFS1 mutations were not found. All probes showed gene dosage similar to controls, demonstrating the absence of gene deletions or duplications in the WFS1 gene.

\section{Patient's follow-up}

As the role played by the AVP gene in CDI has been reported previously (13), our two patients with de novo mutation of the AVP gene did not develop additional endocrine dysfunction over time. Indeed, we focused our attention on change in the WFS1 gene that, conversely, was never associated with the disease under investigation. Our patient with WFS1 mutations repeatedly maintained (every 18-36 months) normal physical examination, neurological examination, visual acuity, refraction, color vision testing, pupillary testing and dilated fundus examinations, audiology and vestibular examinations, urological and psychological/cognitive evaluations, and baseline glucose levels and glucose tolerance after oral glucose tolerance test (OGTT) throughout the 10 years of follow-up. In particular, at the last follow-up in July 2014, thyroid, adrenal, and gonadal functions and liver and kidney functions were found to be normal; the baseline glucose level was $97 \mathrm{mg} / \mathrm{dl}$ (normal values 60-110; $5.38 \mathrm{mmol} / 1$ with normal values $3.5-5.5)$ and, at $120 \mathrm{~min}$ after $75 \mathrm{~g}$ OGTT, it was $119 \mathrm{mg} / \mathrm{dl}$ (6.6 mmol/l). HbA1c was $5.06 \%$ in July 2014 and remained normal throughout the 10 -year follow-up period (median of $5.0 \%$ with a range of 4.6-5.1). The results of visual evoked potential, and auditory brainstem response are reported in Figs 7 and 8 .

\section{Discussion}

We herein demonstrated that heterozygous deleterious mutations in the AVP gene and, for the first time, compound heterozygous mutations in the WFS1 gene can be responsible for an apparently 'idiopathic' CDI in children with non-hereditary early-onset disease due to vasopressin deficiency.

Despite the fact that the parents of our two patients were not affected, the main interesting findings appeared to be, on one hand, the identification of two de novo dominant mutations of the AVP gene and, on the other, the description of a novel AVP mutation localized to the signal peptide (c.52_54delTCC) in addition to the few ones reported in the literature. Indeed, the great majority of mutations reported thus far have been found in the part of the gene encoding NPII, which is an intracellular binding protein for AVP, while only few mutations have been localized to the signal peptide or the AVP-coding 
A WT ILE333

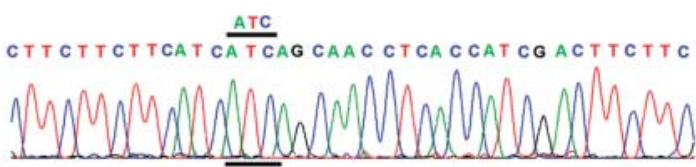

PROBAND

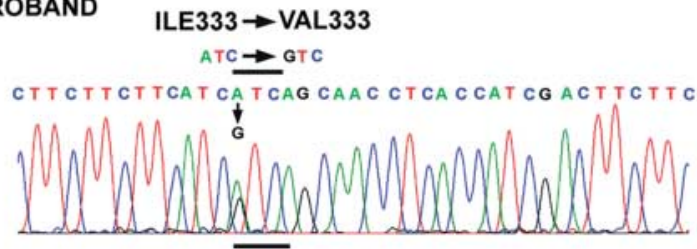

B WT

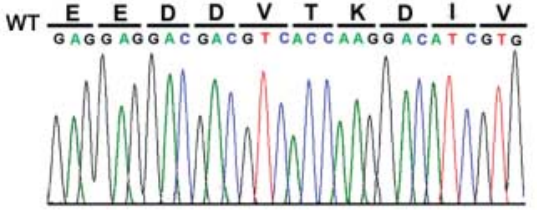

PROBAND

$W T \frac{E}{G A G G} \frac{E}{G A G} \frac{D}{G A C} \frac{D}{G A C} \frac{V}{G T C} \frac{T}{A C C} \frac{K}{A A G G A C} \frac{D}{A T C} \frac{V}{G T G}$

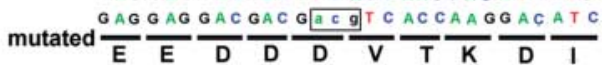

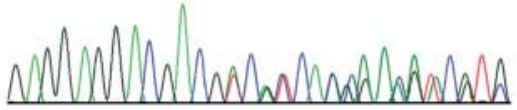

C

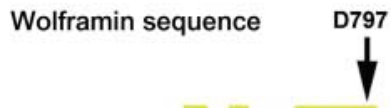

Human 785 SGADGSRSREEDDVTKDIVLRASSE

Mouse 787 T--NGNRGHEEDDI TKDIVLRASSE

Rat 787 T--NGNRGHEEDDI TKDIVLRASSE

Chicken 770 S-KNGTKLVEEDDI TKDIVLKASNE

Frog 759 G-I NGSKMIEEDDI TKDIVLRASNE

Zebrafish 798 G---RNGAQDFDDGTKDIVLRASNE

\section{Figure 3}

Alterations of the wolframin (WFS1) gene in the patient with central diabetes insipidus. (A) The sequences report the WT condition and the patient WFS1 (top and bottom respectively). Particularly, the genetic change is with regard to the A-to-G transition at nucleotide position 997 in exon 8 (997A > G), that results in the occurrence of a valine residue instead of an isoleucine residue at position 333. (B) The figure shows the WT and the other mutated WFS1 exon 8 region (both nucleotide and amino acid sequences). The insertion of three bases (represented by small letters) resulted in the addition of a novel aspartic acid residue and the maintenance of the remaining subsequent sequence. (C) Alignment in different species shows wolframin evolutionary conservation of the sequence mutated in the patient and reported in (B). sequence, and none in the region encoding copeptin (Human Gene Mutation Database). All the reported mutations are expected to replace or eliminate one or more amino acids known, or reasonably assumed, to be critical for a proper processing, dimerization, disulfide bond formation, and folding of the vasopressin precursor in the endoplasmic reticulum (ER) (3). In autosomal dominant CDI, abnormal processing of vasopressin precursors in the supraoptic and paraventricular nuclei, and mutant AVP precursors impair intracellular trafficking of the WT precursor from the ER to the Golgi apparatus by forming heterodimers, with a reduction in the bioavailability of active $\operatorname{AVP}(14,15,16)$. The pathophysiological loss of PPI at MRI in our patients can also be explained by the abnormal processing of vasopressin precursors in the hypothalamic nuclei leading to the impairment of intracellular trafficking with a similar mechanism $(2,14,15,16)$. In our two patients, the signs and symptoms of CDI became evident by the age of 4 years, suggesting that both mutations are completely penetrant and that children with early-onset CDI must be evaluated for $A V P$ mutations even in the absence of this condition among relatives. Although the most frequent form of familial CDI by far is the autosomal dominant condition (3), to our knowledge, de novo dominant mutations of the $A V P$ gene have been reported as recurrent mutations in three families (17).

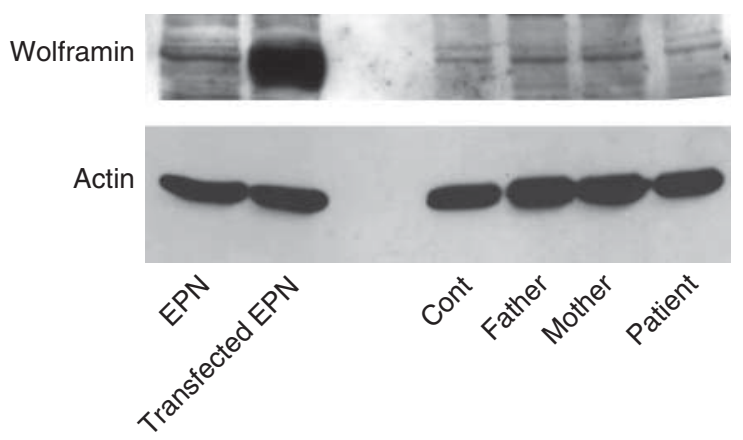

\section{Figure 4}

Analysis of wolframin protein levels in primary fibroblasts of patients with WFS1 mutations. Equal amounts of protein extracts, prepared from primary fibroblasts from a control subject (Cont), the patient with WFS1 mutations (patient), and his parents (father and mother), were analyzed for wolframin and actin content. In addition, EPN cell extracts (from control cells and cells transfected with an expression vector encoding wolframin) were analyzed. EPN cell transfection was performed for confirming the specificity of antibodies employed. 

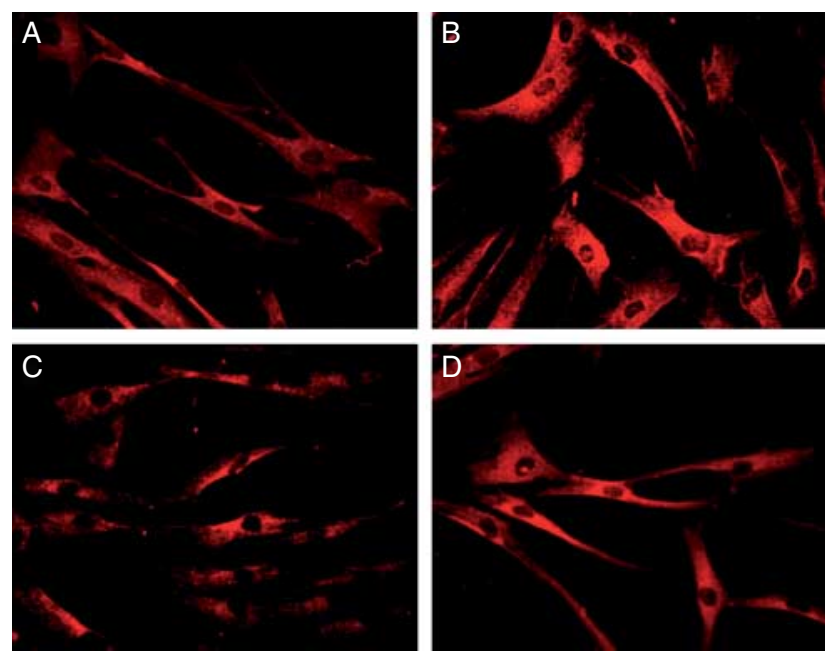

\section{Figure 5}

Localization of wolframin in primary fibroblasts of patients with WFS1 mutation. Primary fibroblasts from two control subjects ( $A$ and $B$ ) and the patient carrying WFS1 mutations ( $C$ and $D$ ) were fixed and, then, the antigen reactivity was retrieved as described under the Subjects and methods section. Subsequently, the slides were incubated with the antiwolframin primary antibody (1:25 dilution) and the secondary antibody. Finally, the cells were incubated for $1 \mathrm{~h}$ with Qdot streptavidin conjugate and the images were captured using a Leica Laser Scanning Confocal Microscope TCS SP2. Magnification $200 \times$.

On the other hand, WFS1 mutations might lead to loss of normal posterior pituitary function by progressive AVP-neuron cell degeneration and depletion (18). Another major finding of our study is the identification of a WFS1 gene mutation associated with an apparently idiopathic isolated CDI after a prolonged follow-up, suggesting the absence of age-dependent variability in clinical expression. The spectrum of clinical symptoms of Wolfram syndrome is extremely variable encompassing cases with the classical diabetes insipidus, diabetes mellitus, optic atrophy, and deafness (DIDMOAD) signs with neurological, urological, and psychiatric manifestations, and cases with only a partial, incomplete, phenotype (4). In particular, the time of onset of CDI varies considerably, generally not appearing until the second or third decade $(19,20)$, while diabetes mellitus has been reported to be the presenting symptom at a median age of 6 years, followed by optic atrophy at a median age of 11 years (21).

While autosomal dominant WFS1 mutations have been associated with non-syndromic low-frequency sensorineural hearing loss, congenital hearing impairment, diabetes mellitus and/or optic atrophy, and congenital nuclear cataract $(22,23,24,25)$, common heterozygous variants of WFS1 have been reported either in type 2 diabetes mellitus in populations of European and African American descent $(26,27,28)$, or with an increased frequency of psychiatric disorders including endogenous depression, alteration of short-term memory, anxiety, and suicide attempts (29), suggesting the role of WFS1 in determining incomplete phenotypes.

Our patient is the first ever reported subject with WFS1 mutations and CDI presenting at the age of 30 months without any additional signs of Wolfram syndrome, even after 10 years of follow-up. The proband was found to be compound heterozygous with one allele (inherited from the mother) showing a c.997A $>$ G WFS1 change and the other allele (inherited from the father) displaying the insertion of three bases after the position 2392 .

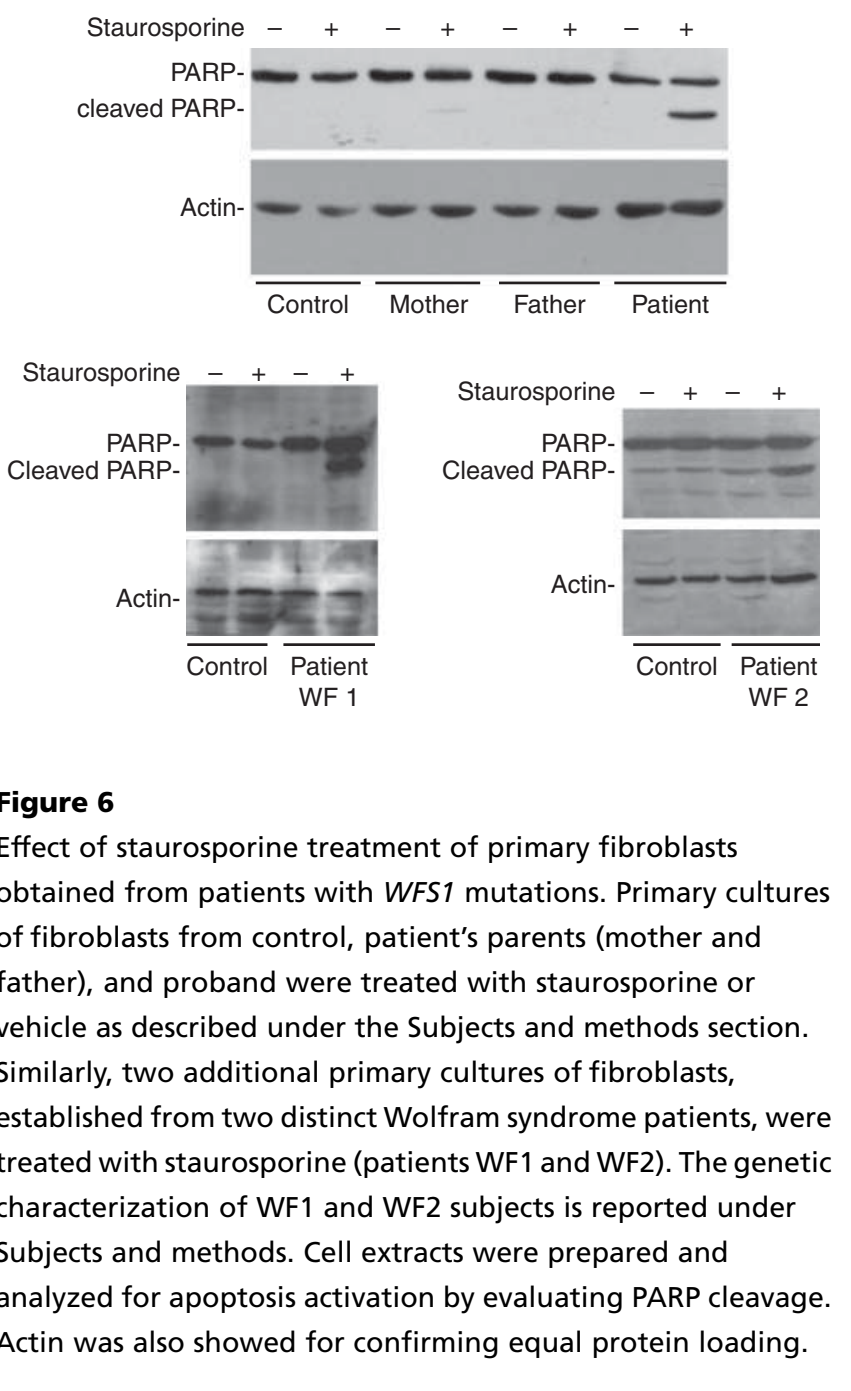



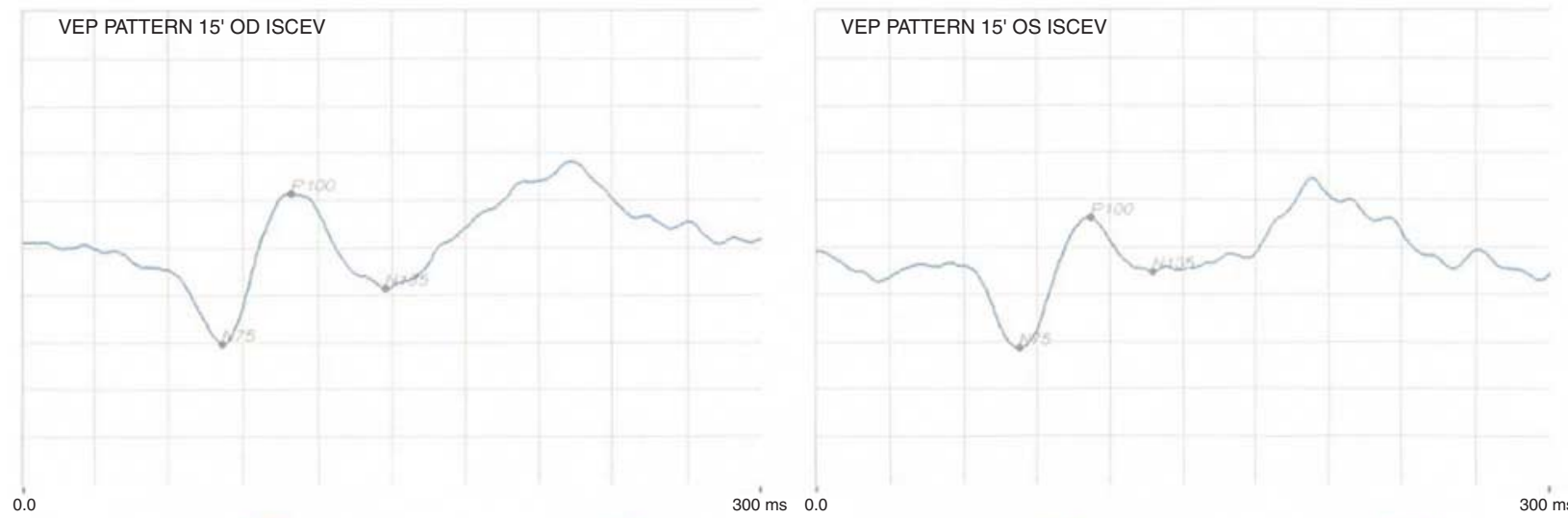

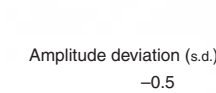

$-0.5$

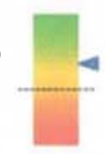

RIGHT - OD
Amplitude $(\mu V)$

Peak time (ms)

Acq. time (ms): 300.0

Flash strength $\left(\mathrm{cd} . \mathrm{s} / \mathrm{m}^{2}\right)$ :

Spatial form: Checkerboard
Peak time deviation (s.d.)

0.4

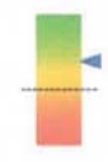

N75-P100 P100-N135

\begin{tabular}{l|l}
10.57 & 6.71
\end{tabular}

27.54

Gain: 50000.0

Background $\left(\mathrm{cd} / \mathrm{m}^{2}\right)$ :---
Temp. form: Reverse

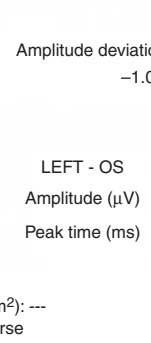

\section{Figure 7}

Visual evoked potential testing is normal, suggesting that the visual pathway is not affected (VEP Pattern Reversal (Checkboard) with spatial frequency $16,58 \mathrm{~min}$, time frequency, $1 \mathrm{~Hz}$,

The consequent effect is the addition of a new aspartic acid residue (at position 798) succeeding two aspartate residues (at positions 796 and 797) and two glutamate residues (at positions 794 and 795), with the remaining part of the protein left unmodified. The relevance of the current identified change is emphasized by three considerations. First of all, the change is a novel mutation. Secondly, the mutation affects an acidic region that is evolutionarily conserved in human, rat, mouse, chicken, frog, and zebrafish wolframin (24), suggesting that alterations of these residues might have deleterious consequences for the protein function. Thirdly, the absence of other symptoms (except for polyuria and polydipsia) confirms the importance of the specific sequence mutations in the wolframin activity. It is of interest to emphasize that loss-of-function mutations that disrupt the wolframin protein, a glycosylated protein of molecular weight $100 \mathrm{kDa}$ localized to the ER membrane, were reported in the majority of the described DIDMOAD cases. While the N-terminal domain of the protein is localized to the cytoplasm, its C-terminal is positioned in the ER lumen (30). Importantly, the C-terminal of wolframin is conserved in human, mouse, contrast 99\%; filters: high pass $1 \mathrm{~Hz}$ - low pass $30 \mathrm{~Hz}$; right eye amplitude $10.57 \mu \mathrm{V}$, latency $108.98 \mathrm{~ms}$; left eye amplitude $9.12 \mu \mathrm{V}$, latency $111.91 \mathrm{~ms})$.

and rat and there is evidence indicating that wolframin may function as a calcium channel $(19,31)$. Indeed, ectopic expression of wolframin causes increased calcium concentration in the cytosol and exhibits cation-selective channel activities in the ER membrane, indicating that wolframin may function in ER calcium homeostasis (31). As Wolframin may also regulate ion homeostasis of the canalicular reticulum, inactivation or suppression of wolframin may cause an imbalance in ER calcium homeostasis (32). In vitro, wolframin is organized as a tetramer, from which originates a membrane $\mathrm{Ca}^{2+}$ channel of the ER, and lack of function of WFS1 determines apoptotic input signaling also connected to the unfolded protein response $(23,32)$. This view is further confirmed by studies demonstrating that WFS1 deficiency increases apoptosis due to ER stress (33).

As far as the Ile333Val WFS1 change is found in our patient, a mutation reported previously (34), its role has not been definitely elucidated, with some authors suggesting that the alteration is functionally relevant in determining the Wolfram syndrome $(35,36,37)$, while others suggest that the mutation is only a polymorphism 


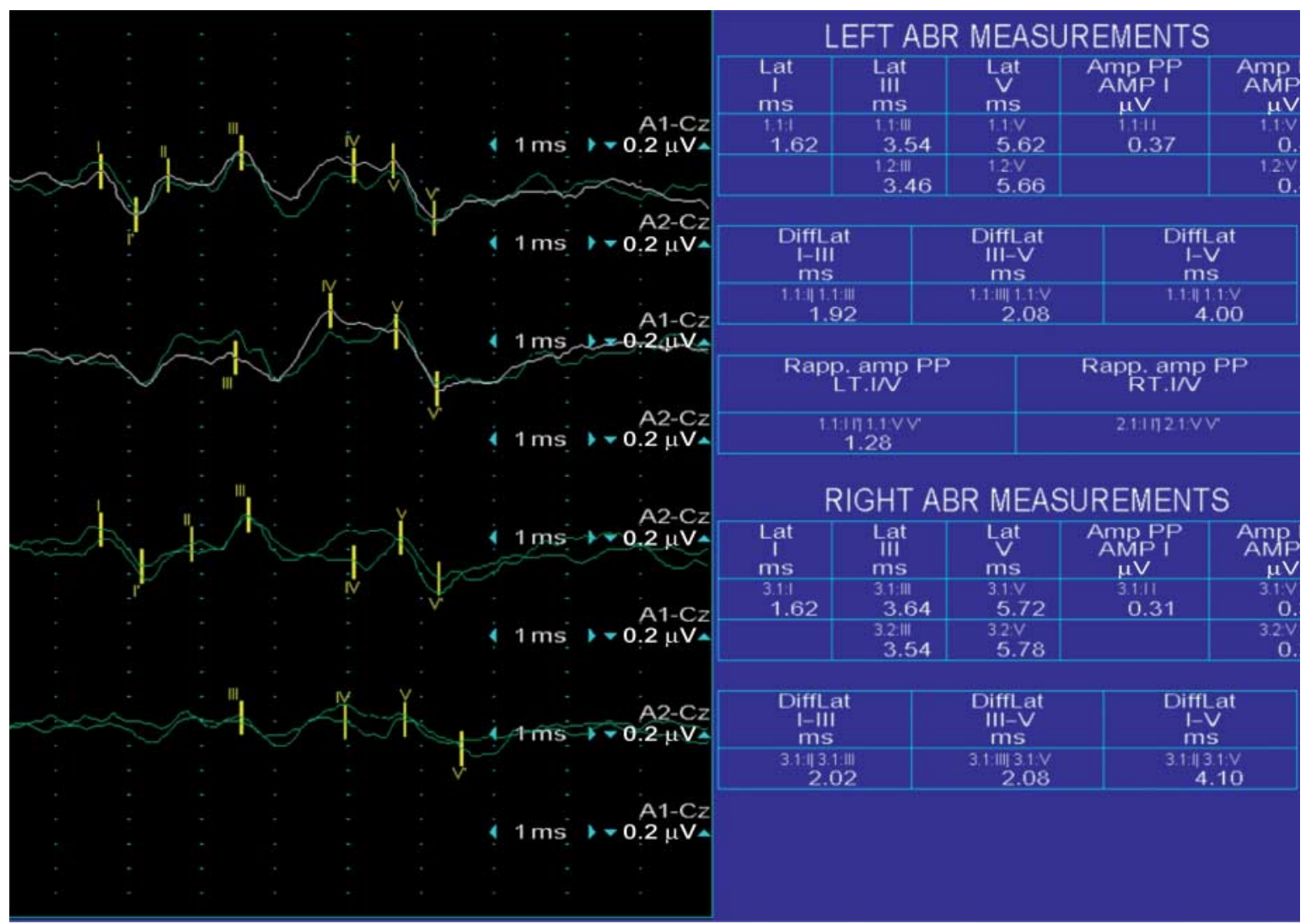

\section{Figure 8}

Normal auditory brainstem response $(A B R)$ and audiometry waveform response: alternant click $80 \mathrm{~dB}$ normal hearing level $(\mathrm{nHL})$ Freq. $11.1 \mathrm{~Hz}$. The amplitude $(\mu \mathrm{V})$ of the signal is averaged and charted against the time (ms). The waveform peaks are

not directly responsible for the disease (38). Our investigation favors the view that the change c.997A $>$ G actually plays a role in the development of Wolfram syndrome based on the results of functional studies demonstrating that only the occurrence of both mutations increased apoptosis, as revealed by the enhanced response to staurosporine in the proband's fibroblasts. In addition, while the staurosporine test performed on fibroblasts from two patients with Wolfram syndrome carrying two different mutations confirmed that WFS1 gene mutations might cause an increased apoptotic response, primary cultures of fibroblasts from the mother's and the father's proband behave as the fibroblasts from healthy subjects although having one altered WFS1 allele.

The lack of mutations in the coding region of $A V P$ and WFS1 genes in the remaining six patients does not rule out the possible occurrence of intronic region alterations of these genes and/or of epigenetic events labeled. These waveforms normally occur within a 10-ms time period after a click stimulus presented at high intensities (70-90 dBnHL).

that could affect their expression. Preliminary data generated by our laboratory did not confirm such suggestions (data not shown) and further studies are required. On the other hand, linkage analysis in a Chinese family with autosomal dominant CDI, with no mutations in the AVP gene, indicated that the putative gene(s) responsible for the autosomal dominance was/were located in a specific 7-cM interval on chromosome 20 suggesting the presence of locus heterogeneity of autosomal dominant CDI (39).

In conclusion, our study demonstrates that earlyonset 'idiopathic' CDI might be due to either de novo mutations of $A V P$ or hereditary changes in WFS1 genes resulting in a profound impact on genetic counseling. The identification of changes in the wolframin gene in our subject with CDI, in the absence of other DIDMOAD syndrome symptoms, demonstrates that WFS1 mutation associated with isolated CDI is very 
rare and that this gene should be analyzed only in selected cases despite the absence of additional signs. An early MRI evidence of PPI indicates that this finding may represent a hallmark of genetic mutations affecting the AVP gene, although the signal disappears on a regular basis at follow-up. Finally, our data indicate the need for a careful genetic screening of children presenting with early-onset CDI in order to rule out putative alterations of WFS1 and AVP genes.

\section{Declaration of interest}

The authors declare that there is no conflict of interest that could be perceived as prejudicing the impartiality of the research reported.

\section{Funding}

This work was partly supported by grants from 'Dipartimento della Donna, del Bambino e di Chirurgia Generale e Specialistica' of the Second University of Naples (Normal and Pathological Hematopoiesis) (to $S$ Perrotta) and Regione Campania 'Laboratorio pubblico per I'identificazione di inibitori del pathway dell'Oxygen Sensing per la terapia di malattie rare' (to S Perrotta).

\section{Author contribution statement}

$S$ Perrotta and M Maghnie contributed to the conception and design of the study and the interpretation of the data, and drafted the manuscript. N Di lorgi contributed to the design of the study and drafted, reviewed, and approved the manuscript. F D Ragione contributed to the design of experiments based on cell cultures, transfection, and protein analyses. $S$ Scianguetta participated in the genetic characterization of patients. A Borriello performed part of the biochemical and immunochemical studies on human fibroblasts. M Ferraro established the primary culture of fibroblasts from patients and performed the transfection experiments. C Santoro performed part of genetic characterization of patients. A E M Allegri, F Napoli, and A Calcagno contributed to the study by taking care of the patients, reviewed, and approved the manuscript. M Giaccardi contributed to the acquisition of the data and prepared the tables. M Cappa, D Cozzolino, and M C Salerno have contributed with their patients, and reviewed and approved the manuscript.

\section{Acknowledgements}

Prof. Fumihiko Urano, University of Massachusetts Medical School, USA, provided rabbit polyclonal antibodies against wolframin and rabbit polyclonal antibodies against poly-PARP were kindly provided by Prof. Piera Quesada, University of Naples 'Federico II, Naples. The authors are deeply grateful to the patients and their parents for their contribution to the study and to Prof. Roberto Ravazzolo for revising the paper.

\section{References}

1 Maghnie M, Cosi G, Genovese E, Manca-Bitti ML, Cohen A, Zecca S, Tinelli C, Gallucci M, Bernasconi S, Boscherini B et al. Central DI in children and young adults. New England Journal of Medicine 2000343 998-1007. (doi:10.1056/NEJM200010053431403)
2 Di Iorgi N, Napoli F, Allegri AE, Olivieri I, Bertelli E, Gallizia A, Rossi A \& Maghnie M. DI diagnosis and management. Hormone Research in Pediatrics 201277 69-84. (doi:10.1159/000336333)

3 Babey M, Kopp P \& Robertson GL. Familial forms of diabetes insipidus: clinical and molecular characteristics. Nature Reviews. Endocrinology 20117 701-714. (doi:10.1038/nrendo.2011.100)

4 Aloi C, Salina A, Pasquali L, Lugani F, Perri K, Tallone R, Ghiggeri GM, Lorini R \& d'Annunzio G. Wolfram syndrome: new mutations, different phenotype. PLoS ONE 20127 e29150. (doi:10.1371/journal.pone. 0029150)

5 Di Iorgi N, Maria Allegri AE, Napoli F, Calcagno A, Calandra E, Fratangeli N, Vannati M, Rossi A, Bagnasco F, Haupt R et al. Central diabetes insipidus in children and young adults: etiological diagnosis and long-term outcome of idiopathic cases. Journal of Clinical Endocrinology and Metabolism 201399 1264-1272. (doi:10.1210/jc.2013-3724)

6 Maghnie M, Ghirardello S, De Bellis A, di Iorgi N, Ambrosini L, Secco A, De Amici M, Tinelli C, Bellastella A \& Lorini R. Idiopathic central DI in children and young adults is commonly associated with vasopressincell antibodies and markers of autoimmunity. Clinical Endocrinology 200665 470-478. (doi:10.1111/j.1365-2265.2006.02616.x)

7 Maghnie M, Altobelli M, Di Iorgi N, Genovese E, Meloni G, MancaBitti ML, Cohen A \& Bernasconi S. Idiopathic central DI is associated with abnormal blood supply to the posterior pituitary gland caused by vascular impairment of the inferior hypophyseal artery system. Journal of Clinical Endocrinology and Metabolism 200489 1891-1896. (doi:10.1210/jc.2003-031608)

8 Borriello A, Caldarelli I, Basile MA, Bencivenga D, Tramontano A, Perrotta S, Della Ragione F \& Oliva A. The tyrosine kinase inhibitor dasatinib induces a marked adipogenic differentiation of human multipotent mesenchymal stromal cells. PLoS ONE 20116 e28555. (doi:10.1371/journal.pone.0028555)

9 Cucciolla V, Borriello A, Criscuolo M, Sinisi AA, Bencivenga D, Tramontano A, Scudieri AC, Oliva A, Zappia V \& Della Ragione F. Histone deacetylase inhibitors upregulate p57Kip2 level by enhancing its expression through Sp1 transcription factor. Carcinogenesis 2008 29 560-567. (doi:10.1093/carcin/bgn010)

10 de Fost M, van Trotsenburg AS, van Santen HM, Endert E, van den Elzen C, Kamsteeg EJ, Swaab DF \& Fliers E. Familial neurohypophyseal diabetes insipidus due to a novel mutation in the arginine vasopressinneurophysin II gene. European Journal of Endocrinology 2011165 161-165. (doi:10.1530/EJE-11-0048)

11 Morling N, Allen RW, Carracedo A, Geada H, Guidet F, Hallenberg C, Martin W, Mayr WR, Olaisen B, Pascali VL et al. Paternity Testing Commission of the International Society of Forensic Genetics: recommendations on genetic investigations in paternity cases. Forensic Science International 2002129 148-157. (doi:10.1016/S0379-0738(02) 00289-X)

12 Philbrook C, Fritz E \& Weiherc H. Expressional and functional studies of Wolframin, the gene function deficient in Wolfram syndrome, in mice and patient cells. Experimental Gerontology 200540 671-678. (doi:10.1016/j.exger.2005.06.008)

13 Riddell DC, Mallonee R, Phillips JA, Parks JS, Sexton LA \& Hamerton JL. Chromosomal assignment of human sequences encoding arginine vasopressin-neurophysin II and growth hormone releasing factor. Somatic Cell and Molecular Genetics 198511 189-195. (doi:10.1007/ BF01534707)

14 Ito M, Yu RN \& Jameson JL. Mutant vasopressin precursors that cause autosomal dominant neurohypophyseal diabetes insipidus retain dimerization and impair the secretion of wild-type proteins. Journal of Biological Chemistry 1999274 9029-9037. (doi:10.1074/jbc. 274.13.9029)

15 Russell TA, Ito M, Ito M, Yu RN, Martinson FA, Weiss J \& Jameson JL. A murine model of autosomal dominant neurohypophyseal diabetes insipidus reveals progressive loss of vasopressin-producing neurons. Journal of Clinical Investigation 2003112 1697-1706. (doi:10.1172/ JCI200318616) 
16 Friberg MA, Spiess M \& Rutishauser J. Degradation of wild-type vasopressin precursor and pathogenic mutants by the proteasome. Journal of Biological Chemistry 2004279 19441-19447. (doi:10.1074/ jbc.M310249200)

17 Rutishauser J, Kopp P, Gaskill MB, Kotlar TJ \& Robertson GL. Clinical and molecular analysis of three families with autosomal dominant neurohypophyseal diabetes insipidus associated with a novel and recurrent mutations in the vasopressin-neurophysin II gene. European Journal of Endocrinology 2002146 649-656. (doi:10.1530/eje.0.1460649)

18 Hofmann S \& Bauer MF. Wolfram syndrome-associated mutations lead to instability and proteasomal degradation of wolframin. FEBS Letters 2006580 4000-4004. (doi:10.1016/j.febslet.2006.06.036)

19 Smith CJ, Crock PA, King BR, Meldrum CJ \& Scott RJ. Phenotypegenotype correlations in a series of Wolfram syndrome families. Diabetes Care 200427 2003-2009. (doi:10.2337/diacare.27.8.2003)

20 Medlej R, Wasson J, Baz P, Azar S, Salti I, Loiselet J, Permutt A \& Halaby G. Diabetes mellitus and optic atrophy: a study of Wolfram syndrome in the Lebanese population. Journal of Clinical Endocrinology and Metabolism 200489 1656-1661. (doi:10.1210/jc.2002-030015)

21 Barrett TG, Bundey SE \& Macleod AF. Neurodegeneration and diabetes: UK nationwide study of Wolfram (DIDMOAD) syndrome. Lancet 1995 346 1458-1463. (doi:10.1016/S0140-6736(95)92473-6)

22 Bespalova IN, Van Camp G, Bom SJH, Brown DJ, Cryns K, DeWan AT, Erson AE, Flothmann K, Kunst HPM, Kurnool P et al. Mutations in the Wolfram syndrome 1 gene (WFS1) are a common cause of low frequency sensorineural hearing loss. Human Molecular Genetics 2001 10 2501-2508. (doi:10.1093/hmg/10.22.2501)

23 Valéro R, Bannwarth S, Roman S, Paquis-Flucklinger V \& Vialettes B. Autosomal dominant transmission of diabetes and congenital hearing impairment secondary to a missense mutation in the WFS1 gene. Diabetic Medicine 200825 657-661. (doi:10.1111/j.1464-5491.2008. 02448.x)

24 Rendtorff ND, Lodahl M, Boulahbe H, Johansen IR, Pandya A, Welch KO, Norris VW, Arnos KS, Bitner-Glindzicz M, Emery SB et al. Identification of p.A684V missense mutation in the WFS1 gene as a frequent cause of autosomal dominant optic atrophy and hearing impairment. American Journal of Medical Genetics. Part A 2011155 1298-1313. (doi:10.1002/ajmg.a.33970)

25 Berry V, Gregory-Evans C, Emmett W, Waseem N, Raby J, Prescott D, Moore AT \& Bhattacharya SS. Wolfram gene (WFS1) mutation causes autosomal dominant congenital nuclear cataract in humans. European Journal of Human Genetics 201321 1356-1360. (doi:10.1038/ ejh. 2013.52)

26 Sandhu MS, Weedon MN, Fawcett KA, Wasson J, Debenham SL, Daly A, Lango H, Frayling TM, Neumann RJ, Sherva Ret al. Common variants in WFS1 confer risk of type 2 diabetes. Nature Genetics 200739 951-953. (doi:10.1038/ng2067)

27 Lyssenko V, Jonsson A, Almgren P, Pulizzi N, Isomaa B, Tuomi T, Berglund G, Altshuler D, Nilsson P \& Groop L. Clinical risk factors, DNA variants, and the development of type 2 diabetes. New England Journal of Medicine 2008359 2220-2232. (doi:10.1056/NEJMoa0801869)

28 Long J, Edwards T, Signorello LB, Cai Q, Zheng W, Shu XO \& Blot WJ. Evaluation of genome-wide association study-identified type 2 diabetes loci in African Americans. American Journal of Epidemiology 2012176 995-1001. (doi:10.1093/aje/kws176)

29 Swift RG, Polymeropoulos MH, Torres R \& Swift M. Predisposition of Wolfram syndrome heterozygotes to psychiatric illness. Molecular Psychiatry 19983 86-91. (doi:10.1038/sj.mp.4000344)

30 Takeda K, Inoue H, Tanizawa Y, Matsuzaki Y, Oba J, Watanabe Y, Shinoda K \& Oka Y. WFS1 (Wolfram syndrome 1) gene product: predominant subcellular localization to endoplasmic reticulum in cultured cells and neuronal expression in rat brain. Human Molecular Genetics 200110 477-484. (doi:10.1093/hmg/10.5.477)

31 Osman AA, Saito M, Makepeace C, Permutt MA, Schlesinger P \& Mueckler M. Wolframin expression induces novel ion channel activity in endoplasmic reticulum membranes and increases intracellular calcium. Journal of Biological Chemistry 2003278 52755-52762. (doi:10.1074/jbc.M310331200)

32 Cryns K, Sivakumaran TA, Van den Ouweland JM, Pennings RJ, Cremers CW, Flothmann K, Young TL, Smith RJ, Lesperance MM \& Van Camp G. Mutational spectrum of the WFS1 gene in Wolfram syndrome, nonsyndromic hearing impairment, diabetes mellitus and psychiatric disease. Human Mutation 200322 275-287. (doi:10.1002/ humu.10258)

33 Yamada T, Ishihara H, Tamura A, Takahashi R, Yamaguchi S, Takei D, Tokita A, Satake C, Tashiro F, Katagiri H et al. WFS1-deficiency increases endoplasmic reticulum stress, impairs cell cycle progression and triggers the apoptotic pathway specifically in pancreatic $\beta$-cells. Human Molecular Genetics 200615 1600-1609. (doi:10.1093/hmg/ddlo81)

34 Fonseca SG, Fukuma M, Lipson KL, Nguyen LX, Allen JR, Oka Y \& Urano F. WFS1 is a novel component of the unfolded protein response and maintains homeostasis of the endoplasmic reticulum in pancreatic $\beta$-cells. Journal of Biological Chemistry 2005280 39609-39615. (doi:10.1074/jbc.M507426200)

35 Inoue H, Tanizawa Y, Wasson J, Behn P, Kalidas K, Bernal-Mizrachi E, Mueckler M, Marshall H, Donis-Keller H, Crock P et al. A gene encoding a transmembrane protein is mutated in patients with diabetes mellitus and optic atrophy (Wolfram syndrome). Nature Genetics 1998 20 143-148. (doi:10.1038/2441)

36 Khanim F, Kirk J, Latif F \& Barrett TG. WFS1/wolframin mutations, Wolfram syndrome, and associated diseases. Human Mutation 200117 357-367. (doi:10.1002/humu.1110)

37 Tessa A, Carbone I, Matteoli MC, Bruno C, Patrono C, Patera IP, De Luca F, Lorini R \& Santorelli FM. Identification of novel WFS1 mutations in Italian children with Wolfram syndrome. Human Mutation 200117 348-349. (doi:10.1002/humu.32)

38 Cano A, Rouzier C, Monnot S, Chabrol B, Conrath J, Lecomte P, Delobel B, Boileau P, Valero R, Procaccio V et al. Identification of novel mutations in WFS1 and genotype-phenotype correlation in Wolfram syndrome. American Journal of Medical Genetics 2007 143A 1605-1612. (doi:10.1002/ajmg.a.31809)

39 Ye L, Li X, Chen Y, Sun H, Wang W, Su T, Jiang L, Cui B \& Ning G. Autosomal dominant neurohypophyseal diabetes insipidus with linkage to chromosome 20p13 but without mutations in the AVP-NPII gene. Journal of Clinical Endocrinology and Metabolism 200590 4388-4393. (doi:10.1210/jc.2004-2000)

Received 3 November 2014

Revised version received 8 January 2015

Accepted 14 January 2015 